\title{
Особенности красных игристых вин, выработанных из сорта винограда Каберне-Совиньон
} отделения виноделия, a.v.vasylyk@gmail.com;
yal.anatol@gmail.com;
Александр Семёнович Макаров, д-р техн. наук., профессор, зав. лабораторией игристых вин, makarov150@rambler.ru; Наталия Александровна Шмигельская, канд. техн. наук, науч. сотр. лаборатории игристых вин, nata-ganaj@yandex.ru; Игорь Павлович Лутков, канд. техн. наук, ст. науч. сотр., вед. науч. сотр. лаборатории игристых вин, igorlutkov@mail.ru; Александр Васильевич Васылык, канд. техн. наук, ст. науч. сотр., зам. директора по научной работе; руководитель
Виктория Алексеевна Максимовская, мл. науч. сотр. лаборатории игристых вин;
Анатолий Яковлевич Яланецкий, канд. техн.наук, ст. науч. сотр., вед. науч. сотр. лаборатории тихих вин,
Тамара Рафаиловна Шалимова, мл. науч. сотр. лаборатории игристых вин, tamaramagarach@mail.ru;
Валентина Васильевна Кречетова, вед. инженер лаборатории игристых вин
Федеральное государственное бюджетное учреждение науки «Всероссийский национальный научно-исследовательский институт виноградарства и виноделия «Магарач» РАН», Россия, Республика Крым, 298600, г. Ялта, ул. Кирова, 31

\begin{abstract}
В статье рассмотрены основные и дополнительные показатели игристых вин, полученных из виноматериалов, выработанных по-красному способу из сорта винограда Каберне-Совиньон, произрастающего в разных микрозонах Крыма. Выявлены отличительные показатели игристых вин (величины окислительно-восстановительного потенциала и активной кислотности, массовые концентрации альдегидов и аминного азота, процента мономерных и полимерных форм фенольных веществ от суммы фенольных веществ, интенсивности и оттенка окраски), на основе которых проведена дифференциация указанных образцов на две группы в зависимости от места произрастания винограда: 1 группа - г. Ялта: п. Васильевка, пгт Гурзуф; 2 группа - Бахчисарайский район: с. Вилино, с. Плодовое. Полученные данные возможно использовать как дополнительные показатели при характеристике игристых вин, выработанных из виноматериалов из винограда, произрастающего в разных микрозонах Крыма.
\end{abstract}

Ключевые слова: физико-химические показатели; органолептическая оценка; тираж; фенольный комплекс; оптические показатели.

$\mathrm{B}$ ведение. На современном этапе развития главной задачей виноградовинодельческой отрасли явмяется производство не только высококачественной, конкурентоспособной, но и винопродукции с уникамьными индивидуаАьными особенностями. Особое внимание уделяется винопродукции заданных категорий качества, в том числе с географическим статусом, которые выражены в проявлении и сохранении индивидуацьных органомептических и физико-химических показатемей [1-4]. При этом основными

\section{O R I G I N A L R E S E A R C H}

\section{Peculiarities of red sparkling wines produced from 'Cabernet-Sauvignon' grapes}

Alexander Semionovich Makarov, Natalia Alexandrovna Shmigelskaia, Igor Pavlovich Lutkov, Aleksandr Vasilievich Vasylyk, Viktoria Alekseievna Maksimovskaia, Anatolii Yakovlevich Yalanetskii, Tamara Rafailovna Shalimova, Valentina Vasilievna Krechetova

Federal State Budget Scientific Institution All-Russian National Research Institute of Viticulture and Winemaking Magarach of the RAS, 31 Kirova Str., 298600 Yalta, Republic of Crimea, Russian Federation

The article discusses core and additional characteristics of sparkling wines obtained from wine materials produced using on-skins fermentation from 'Cabernet-Sauvignon' grapes grown in various microzones of Crimea. Distinctive characteristics of sparkling wines have been revealed (redox potential and active acidity values, mass concentration of aldehydes and amine nitrogen, percentage of monomeric and polymer forms of phenolic substances from the sum of phenolic substances, intensity and color tone), based on which the samples were divided into two groups depending on their origin: group 1 - Yalta: Vasilyevka, Gurzuf; 2 group - Bakhchisarai region: Vilino, Plodovoye villages. The obtained data can be used as additional indicators to characterize sparkling wines produced from wine materials made from grapes grown in various microzones of Crimea.

Key words: physical and chemical indicators; organoleptic assessment; tirage; phenolic complex; optical indices.

факторами, влияющими на качество вина, явцяются сортовые особенности винограда, почвенно-кмиматические условия его произрастания, а также технология производства [5-19]. В производстве красных тихих и игристых вин одним из самых распространенных сортов винограда является кмассический сорт Каберне-Совиньон. Изучение физико-химических показателей игристых вин, выработанных из виноматериалов этого сорта, произрастающего в разных микрозонах Крыма, явцяется актуальным направлением.

Целью исследований являлось изучение особенностей красных игристых вин, выработанных из виноматериалов, полученных из сорта винограда Каберне-Совиньон, произрастающего в разных микрозонах Крыма.

\section{Объекты и методы исследований}

Объектами исследований явмялись игристые вина, приготов-

\section{Как цитировать эту статью:}

Макаров А.С., Шмигельская Н.А., Лутков И.П., Васылык А.В., Максимовская В.А., Яланецкий А.Я., Шалимова Т.Р., Кречетова В.В. Особенности красных игристых вин выработанных из сорта винограда Каберне-Совиньон // «Магарач». Виноградарство и виноделие. 2019; 21 (3). С. 256 260. DOI 10.35547/IM.2019.21.3.013

How to cite this article:

Makarov A.S., Shmigelskaia N.A., Lutkov I.P., Vasylyk A.V., Maksimovskaia V.A., Yalanetskii A.Ya, Shalimova T.R., Krechetova V.V. Peculiarities of red sparkling wines produced from 'Cabernet-Sauvignon' grapes. Magarach. Vinogradarstvo i vinodelie=Magarach. Viticulture and Winemaking. 2019; 21(3):256-260. DOI 10.35547/IM.2019.21.3.013 (in Russian)

удК 663.223.11:663.253.1

Поступила 19.08.2019

Принята к публикации 27.08.2019

САвторы, 2019 
менные из виноматериалов сорта Каберне-Совиньон урожаев 2015-2017 гг., выработанных из винограда, произрастающего в Авух микрозонах Крыма: 1 - Южный берег Крыма (п. Васимьевка, г. Я九та, пгт Гурзуф), 2 - западный преАгорноприморский (с. Вимино, с. Пцодовое Бахчисарайского района). Виноматериалы Аля игристых вин вырабатывацись в условиях микровинодемия «по-красному» (п/к) способу с использованием штаммов Арожжей из коммекции микроорганизмов ФГБУН «ВННИИВиВ «Магарач» РАН». Тираж проведен в соответствии с ГОСТ 33311-2015 «Игристые вина. Основные прави$\Lambda$ производства». По истечении не менее 9 мес. после закмадки опытных тиражей в полученных игристых винах опредемяли основные и Аополнительные физико-химические показатели стандартизированными и принятыми в винодемии методами анамиза [20], в том числе пенистые свойства $\left(\mathrm{V}_{\max }-\right.$ максимацьный объём пены, см$^{3}$; $\mathrm{t}_{\text {раз. }}-$ время разрушения пены), согласно СТО 01580301.015-2017 «Столовые виноматериамы Аһя игристых вин, напитки, насыщенные АиоксиАом углерода. Определение пенистых свойств». Обработку Аанных проводими с помощью метоАов математической статистики с испоцьзованием программного обеспечения MS Office Excel и Statistica.

\section{Обсуждение результатов}

Изучены физико-химические и органолептические показатели красных игристых вин (табл.).

По основным физико-химическим показателям практически все выработанные игристые вина соответствоваци нормативной Аокументации ГОСТ 33336 «Вина игристые. Общие технические условия». Массовые концентрации титруемых кислот в исследуемых игристых винах находились в Аостаточно широком Аиапазоне - от 5,1 Ао 8,1 г/Ам³. Бомее низкими значениями Аанного показателя характеризовацись образцы из п. Васимьевка, пгт Гурзуф - 5,1-7,3 г/Ам³. Активная кислотность исследуемых игристых вин находимась в пределах 3,1-3,8. Несколько бо́ ьшее значение величины $\mathrm{pH}$ в пределах 3,8 отмечено в образцах из микрозон п. Васицьевка, пгт Гурзуф. В Аанных образцах активная кислотность, возможно, обусловлена зоной произрастания винограда - Южный берег Крыма, что согласуется с ранее проведенными исследованиями [21].

При оценке показатемя привеАенного экстракта, который вцияет не только на формирование вкусовых характеристик, а также и на специфические свойства игристых вин, выявлено, что в изучаемых образцах среАние значения массовых концентраций привеАенного экстракта находились в преАемах 17,1-24,5 г/Ам³. Незначительно выше Аанный показатемь в образцах из микрозон п. Васимьевка, пгт Гурзуф - в предемах $23,1-24,5$ г/AM ${ }^{3}$.

Аополнительно к основным физико-хими-
Макаров А.С., Шмигельская Н.А., Аутков И.П., Васылык А.В., Максимовская В.А., ЯАанецкий А.Я., Шалимова Т.Р., Кречетова В.В.
Таблица. Физико-химические показатели игристых вин (в числителе - среднее значение показателя, в знаменателе диапазон варьирования)

Table. Physico-chemical parameters of sparkling wines (numerator - mean index value, denominator - variation range)

\begin{tabular}{|c|c|c|c|c|}
\hline \multirow[b]{2}{*}{ Показатемь } & \multicolumn{4}{|c|}{ Место произрастания винограда } \\
\hline & $\begin{array}{l}\text { п. Васи- } \\
\text { мьевка } \\
\text { (г. ЯАта) }\end{array}$ & $\begin{array}{l}\text { пгт } \\
\text { Гурзуф } \\
\text { (г. Я亡та) }\end{array}$ & $\begin{array}{l}\text { с. Вими- } \\
\text { но (Бах- } \\
\text { чиса- } \\
\text { райский } \\
\text { район) }\end{array}$ & $\begin{array}{l}\text { с. ПАодо- } \\
\text { вое (Бах- } \\
\text { чиса- } \\
\text { райский } \\
\text { район) }\end{array}$ \\
\hline Аавление $\mathrm{CO}_{2}, \mathrm{P}_{20}$, кПа & $\frac{495}{470-510}$ & $\frac{525}{480-600}$ & $\frac{533}{520-540}$ & $\frac{508}{495-520}$ \\
\hline $\begin{array}{l}\text { Объемная Аомя этимово- } \\
\text { го спирта, } \%\end{array}$ & $\frac{12,8}{11,2-13,1}$ & $\frac{13,3}{12,8-14,6}$ & $\frac{12,5}{12,3-12,9}$ & $\frac{13,5}{13,3-13,9}$ \\
\hline Вемичина рН & $\frac{3,8}{3,5-3,9}$ & $\frac{3,8}{3,4-4,0}$ & $\frac{3,1}{3,1-3,2}$ & $\frac{3,1}{3,1}$ \\
\hline Вемичина Eh & $\frac{177}{174-182}$ & $\frac{173}{160-201}$ & $\frac{209}{206-212}$ & $\frac{210}{208-211}$ \\
\hline \multicolumn{5}{|c|}{ Maсcовая кониентраиия } \\
\hline сахаров, г/AM ${ }^{3}$ & $\frac{1,0}{0,9-1,1}$ & $\frac{1,3}{1,1-1,7}$ & $\frac{1,0}{0,9-1,1}$ & $\frac{1,0}{1,0-1,1}$ \\
\hline титруемых кис $о$ т, г/Ам ${ }^{3}$ & $\frac{5,1}{4,9-5,5}$ & $\frac{6,2}{5,8-6,9}$ & $\frac{8,1}{7,8-8,3}$ & $\frac{7,3}{7,1-7,6}$ \\
\hline метучих кис $о$ т, г/Ам ${ }^{3}$ & $\frac{0,5}{0,2-0,6}$ & $\frac{0,6}{0,4-1,0}$ & $\frac{0,55}{0,49-0,61}$ & $\frac{0,32}{0,1-0,4}$ \\
\hline $\begin{array}{l}\text { приведенного экстракта, } \\
\Gamma / \mathrm{AM}^{3}\end{array}$ & $\frac{24,5}{14,5-25,3}$ & $\frac{23,1}{19,6-25,5}$ & $\frac{21,2}{20,6-21,6}$ & $\frac{17,1}{16,1-22,4}$ \\
\hline амьАегиАОв, мГ/Ам ${ }^{3}$ & $\frac{15,8}{12,2-23,1}$ & $\frac{17,8}{13,2-28,2}$ & $\frac{50,7}{33,4-66,1}$ & $\frac{51,9}{22,2-81,8}$ \\
\hline помисахаридов, мг/Ам ${ }^{3}$ & - & $\frac{324}{294-355}$ & $\frac{292}{288-296}$ & - \\
\hline аминного азота, мг/Ам ${ }^{3}$ & $\frac{268}{202-285}$ & $\frac{245}{201-313}$ & $\frac{142}{133-154}$ & $\frac{176}{168-185}$ \\
\hline 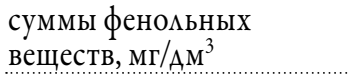 & $\frac{715}{680-782}$ & $\frac{1217}{1017-1827}$ & $\frac{1149}{1008-1213}$ & $\frac{1112}{980-1331}$ \\
\hline 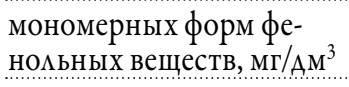 & $\frac{447}{300-505}$ & $\frac{705}{585-811}$ & $\frac{606}{616-656}$ & $\frac{511}{463-559}$ \\
\hline 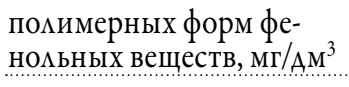 & $\frac{268}{331-410}$ & $\frac{512}{420-1226}$ & $\frac{543}{381-567}$ & $\frac{600}{553-646}$ \\
\hline $\begin{array}{l}\text { красящих веществ, } \\
\mathrm{M \Gamma} / \mathrm{AM}^{3}\end{array}$ & $\frac{89}{80-112}$ & $\frac{126}{118-135}$ & $\frac{126}{112-142}$ & $\frac{216}{204-226}$ \\
\hline \multicolumn{5}{|c|}{ Pасчетные показатели } \\
\hline $\begin{array}{l}\text { соотношение МФФВ / } \\
\Phi B * 100, \%\end{array}$ & $\frac{62,5}{42,0-70,6}$ & $\frac{57,9}{32,9-60,0}$ & $\frac{52,8}{43,5-55,6}$ & $\frac{46,0}{41,6-50,3}$ \\
\hline $\begin{array}{l}\text { соотношение ПФФВ / } \\
\Phi B * 100, \%\end{array}$ & $\frac{37,7}{29,4-58,0}$ & $\frac{42,1}{40,0-67,1}$ & $\frac{47,2}{44,4-56,5}$ & $\frac{54,0}{49,7-58,4}$ \\
\hline $\begin{array}{l}\text { соотношение КВ/ } \\
\Phi B * 100, \%\end{array}$ & $\frac{12,4}{11,1-15,6}$ & $\frac{10,3}{7-11,6}$ & $\frac{12,0}{11,1-12,8}$ & $\frac{19,4}{18,3-20,4}$ \\
\hline
\end{tabular}

Oптические характеристики

$\begin{array}{llllll}\text { интенсивность окраски } & \frac{0,54}{0,42-0,65} & \frac{0,8}{0,7-0,8} & \frac{0,97}{0,91-1,1} & \frac{1,62}{1,56-1,67} \\ (И) & \frac{0,9}{0,8-0,95} & \frac{1,0}{0,8-1,1} & & \frac{0,60}{0,57-0,64} & \frac{0,58}{0,42-0,64}\end{array}$

Типичные свойства максимамьный объем
пены, см время разрушения пены, с $>60 \quad \frac{42,2}{13,5>60}>60>60$

Органолептическая характеристика качества

$\begin{array}{lllll}\text { Аегустационная оцен- } & \frac{8,91}{8,8-8,95} & \frac{9,0}{8,8-9,2} & \frac{8,95}{8,92-8,99} & \frac{8,9}{8,89-8,9} \\ \text { ка, бам }\end{array}$

Примечания: МФФВ - мономерные формы фенольных веществ; $Ф B$ - фенольные вещества; ПФФВ - помимерные формы фенольных веществ; КВ - красящие вещества. 
ческим показателям, указанным в нормативной Аокументации, изучено содержание аминного азота, который обладает поверхностно-активными свойствами и участвует в формировании типичных свойств игристых вин. Массовая концентрация аминного азота находимась в Аиапазоне от 142 но 268 мг/Ам³. Наиболее высокая массовая концентрация аминного азота быма в образцах игристых вин, приготовленных из винограда из микрозон п. Васимьевка, пгт Гурзуф - в диапазоне 245-268 мг/Ам³ содержание аминного азота, с одной стороны, благоприятно вмияет на формирование ароматобразующего компмекса игристых вин, с Аругой стороны, массовая концентрация аминного азота, превышающая значение 200 мг/Aм ${ }^{3}$ [22, 23], явцяется фактором Аця появцения тонов переокисленности.

Также исследовано содержание полисахаридов, массовая концентрация которых в изучаемых игристых винах находицась в Аиапазоне от 292 (с. Вимино) до 394 мг/Ам (пгт Гурзуф).

В изучаемых образцах была определена величина редокс-потенциама, которая характеризует степень окисленности среды и направление протекания окислитемьно-восстановитемьных реакций. Изучаемый показатель находился в Аиапазоне от 173 Ао 222 мВ, что соответствует оптимацьным его значениям Амя игристых вин $[22,23]$. Отмечено, что более низкими значениями данного показатемя характеризовацись образцы из зон п. Васимьевка (177 мВ) и пгт Гурзуф (173 мВ).

В качестве Аополните ьного критерия степени окисленности изучаемых образцов может использоваться содержание в них ацьдегидов. Согласно Аитературным Аанным $[22,23]$, образцы с явным тоном переокисленности содержат повышенное количество ацьдегидов (более 60 мг/Ам ${ }^{3}$ ), которые образуются в резуцьтате окислительного Аезаминирования аминокислот при Аоступе кислорода. Отмечено, что в опытных игристых винах средние значения изучаемого показателя были в предемах рекомендуемого значения - менее 60 мг/Aм ${ }^{3}$. При этом более низкими значениями массовой концентрацией амьдегиАов характеризовались образцы из микрозон п. Васимьевка, пгт Гурзуф - в преАе $а х ~ 15,8-17,8 ~ г / А M^{3}$.

Известно, что особенностью красных вин является повышенное содержание фенольных и красящих веществ [24-27]. Массовые концентрации суммы фенольных веществ в изученных игристых винах находятся в Аостаточно широком Аиапазоне от 715 Ао $1217 \mathrm{Mг} / \mathrm{AM}^{3}$, антоцианов - от 89 Ао 216 мг/AM ${ }^{3}$, мономерных форм фенольных соеАинений - от 447 Ао 705 мг/Ам ${ }^{3}$, Полимерных форм фенольных соеАинений - от 268 Ао 600 мг/Ам³ номерной $(М Ф Ф В / Ф В)$ и полимерной фракции фенольных соеАинений (ПФФВ/ФВ) установ ено, что образцы из с. Вимино и с. Пцодовое обла-
Аами бомее низким процентным содержанием мономерной фракции фенольных соеАинений, более высоким процентным содержаниями полимерной фракции фенольных соеАинений, чем игристые вина из п. Васимьевка, пгт Гурзуф. Полученная закономерность соответственно отразимась на оптических характеристиках опытных образцов - показатецях интенсивности и оттенка окраски, характеризующих вкцаА окрашенных форм фенольных веществ в формирование цвета. Значения показателей интенсивности (И) и оттенка (Т) окраски в образцах находикись в пределах соответственно 0,54-1,62 и 0,58-1,0 в зависимости от места выращивания винограда. Образцы виноматериалов из п. Васимьевка и пгт Гурзуф в сравнении с игристыми винами из с. Вицино, с. Пцодовое характеризовацись бомее низкими значениями показателя интенсивности окраски и более высокими значениями показатеця оттенка окраски.

При оценке типичных свойств игристых вин выявцено, что практически все опытные образцы характеризовались хорошими пенистыми свойствами: средние значения показателя максимацьного объема пены находимись в Аиапазоне от 430 до $520 \mathrm{~cm}^{3}$, а время существования пены - в пределах от 42,2 до более 60 с. Также изучено содержание диоксида углерода в игристых винах (в бутылках вместимостью 0,75 $\mathrm{AM}^{3}$ ), в том числе различные его формы (рис. 1).

Установлено, что содержание Аиоксида углерода в игристых винах составцяет:

- общего - 6,6-7,0 г (при существующих и рекомендуемых значениях - Ао 10 г/AM $\left.{ }^{3}\right)$;

- газообразного (в наАвинной камере) - 0,19-0,23 г;

- растворенного -5,8-6,23 г;

-связанного - 0,53-0,72 г ими от 8 до $23 \%$ при рекоменАуемых значениях - не менее $8 \%$.

При органоцептической оценке опытные игристые вина характеризовацись сложным букетом и вкусом с соответствующими Аегустационными оценками на уровне 8,9-9,0 бам ов.

Таким образом, установмено, что игристые вина, выработанные из сорта Каберне-Совиньон, обладают достаточно широкими Аиапазонами основных и Аополнительных показателей в зависимости от места произрастания винограАа. В результате кмастерного анализа экспериментальных Аанных проведена Аифференциация изучаемых образцов по значимым физико-химическим показателям

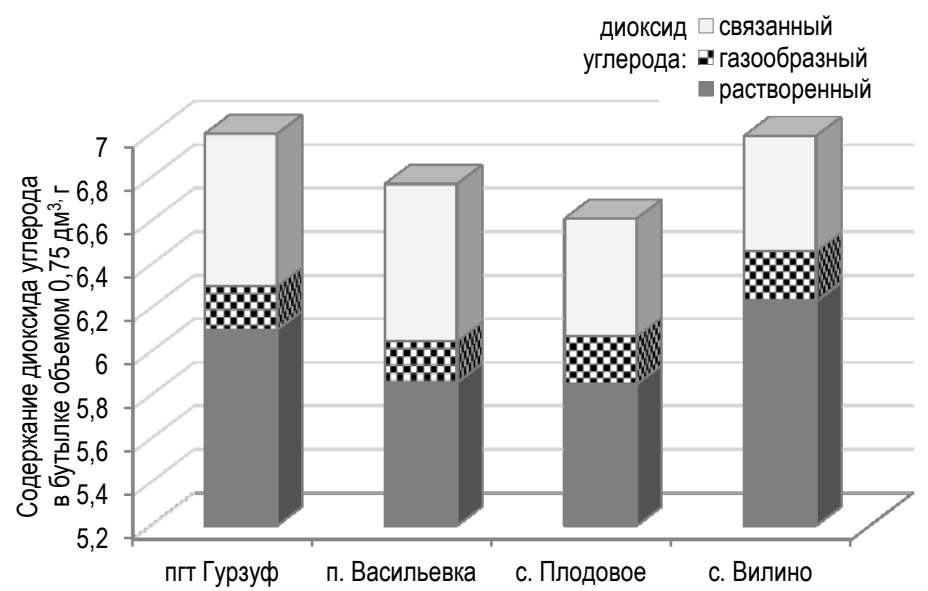

Рис. 1. Содержание различных форм диоксида углерода в опытных игристых винах

Fig. 1. Content of various forms of carbon dioxide in the trial samples of sparkling wines 


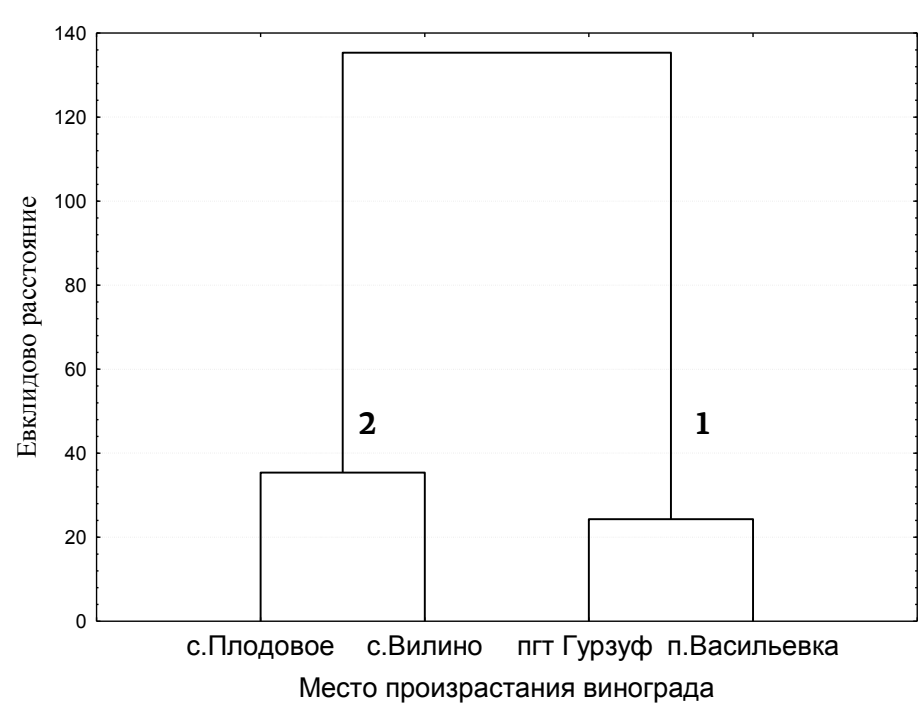

Рис. 2. Дифференцирование игристых вин, выработанных из сорта винограда Каберне-Совиньон, произрастающего в разных микрозонах, по физико-химическим показателям: 1 - Южный берег Крыма, 2 - западный предгорно-приморский район

Fig. 2. Distribution of sparkling wines produced from 'CabernetSauvignon' grapes grown in various microzones by physicochemical parameters: 1 - Southern Coast of Crimea, 2 - western foothill-seaside region

(величины окислительно-восстановительного потенциала и активной кислотности, массовой концентрации ацьдегидов и аминного азота, процента мономерных и полимерных форм фенольных веществ от суммы фенольных веществ, интенсивности и оттенка окраски) (рис. 2). В полученной Аендрограмме выделяется Ава кластера: 1-й кмастер включает образцы игристых вин из п. Васимьевка, пгт Гурзуф, а 2-ой кмастер - с. Вилино, с. Плодовое. Отличительными признаками первой группы являются более высокие значения активной кислотности $\mathrm{pH}$ (на 15-18\%), оттенка окраски (на 26-42\%), массовой концентрации аминного азота (на 28-47\%), содержания мономерной фракции фенольных веществ в фенольном комплексе (Ао 26\%), более низкие значения показателей окислительно-восстановительного потенциала (на 18-20\%), массовой концентрации альдегидов (в 2,8-3,3 раза), содержания полимерной фракции фенольных веществ от суммы фенольных веществ (Ао 43\%), интенсивности окраски (в 1,8-2 раза). Результат кластерного анализа подтвержАает определенное влияние зоны произрастания винограда на формирование физико-химических показателей игристых вин.

В результате исследований выявлены особенности формирования физико-химических показателей игристых вин из винограда сорта Каберне-Совиньон в зависимости от места его произрастания. Полученные Аанные возможно будет использовать при выборе критери-

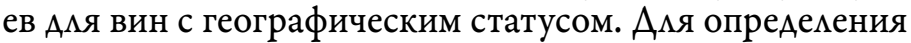
возможности испоцьзования полученных особенностей на Аругие сорта необходимо проведение дополнительных исследований.

\section{Источник финансирования}

Работа выполнена в рамках Государственного задания № 0833-2019-0014.

\section{Financing source.}

The study was conducted under public assignment №0833-2019-0014.
Макаров А.С., Шмигельская Н.А., Аутков И.П., Васылык А.В., Максимовская В.А., ЯАанецкий А.Я., Шалимова Т.Р., Кречетова В.В.

\section{Конфликт интересов} Не заявмен.

\section{Conflict of interests} No declared.

\section{Список литературы/Reference}

1. Авидзба А.М., Яланецкий А.Я., Остроухова Е.В. Проблемы развития виноделия с географическим статусом в Крыму и пути их решения //«Магарач». Виноградарство и виноделие. 2016. № 1. С. 25-30.

[Avidzba A.M., Yalaneckij A.Ya., Ostrouhova E.V. Challenges of winemaking with the geographical status development in Crimea and possible solutions. Magarach. Vinogradarstvo $i$ vinodelie=Magarach. Viticulture and Winemaking. 2016. № 1. pp. 25-30 (in Russian)].

2. Васылык А.В., Остроухова Е.В., Аникина Н.С. Научно-методические основы развития виноделия с географическим статусом в России: основные достижения на пути их реализации // Scientific works of the North Caucasus Federal Scientific Center for Horticulture, Viticulture, Winemaking. 2019. T. 22. C. 79-88. DOI: 10.30679/2587-9847-2019-22-79-88

[Vasylyk A.V., Ostroukhova E.V., Anikina N.S. Scientific and methodological foundations for the development of winemaking with geographical status in Russia: major achievements in their resolutoion. Nauchnye trudy Severo-Kavkazskogo federalnogo nauchnogo centra sadovodstva, vinogradarstva, vinodeliya. 2019. Vol. 22. pp. 79-88 (in Russian)].

3. Яланецкий А.Я., Остроухова Е.В., Загоруйко В.А., Макаров А.С., Шмигельская Н.А. К вопросу классификации винопродукции Российской Федерации // «Магарач». Виноградарство и виноделие. 2016. № 3. C. 27-37.

[Yalaneckij A.Ya., Ostrouhova E.V., Zagorujko V.A., Makarov A.S., Shmigelskaya N.A. On the issue of wine products classification in the Russian Federation. Magarach. Vinogradarstvo $i$ vinodelie= Magarach . Viticulture and Winemaking. 2016. № 3. pp. 27-37 (in Russian)].

4. Яланецкий А.Я., Макаров А.С., Шмигельская Н.А. Перспективы развития производства игристых вин в Крыму //Инновационные технологии в пищевой промышленности материалы XV Международной научно-практической конференции. 2016. С. 122-124.

[Yalanetsky A.Ya., Makarov AS, Shmigelskaya N.A. Prospects for the development of sparkling wine production in Crimea. Innovative technologies in the food industry, materials of the XV International scientificpractical conference. 2016. pp. 122-124 (in Russian)].

5. Остроухова Е.В., Пескова И.В., Рыбалко Е.А., Твардовская Л.Б. Влияние климатических факторов на технологические характеристики винограда красных сортов, произрастающих в различных регионах $\mathrm{Pe}-$ спублики Крым // «Магарач». Виноградарство и виноделие. 2015. № 2. С. 28-31.

[Ostroukhova E.V., Peskova I.V., Rybalko E. A., Tvardovskaya L. B. The effect of climatic factors on the technological characteristics of red grape varieties cultivated in different regions of the Republic of Crimea. Magarach. Vinogradarstvo $i$ vinodelie= Magarach . Viticulture and Winemaking. 2015. № 2. pp. 28-31 (in Russian)].

6. White, R.E. Soils for Fine Wines /R.E. White. Oxford: Oxford University Press. 2003. London: Mitchell Beazley.

7. Doyle, R. Tasmanian viticultural soils and geology / 
R. Doyle, D. Farquhar // Department of Primary Industries and Water. Univercity of Tasmania, 2007. Available athttp://www. dpiw.tas.gov.au/inter.nsf/WebPages/CPAS-5L6VBK?open.

8. Макаров А.С., Яланецкий А.Я., Шмигельская Н.А., Лутков И.П., Шалимова Т.Р., Максимовская В.А., Кречетова В.В. Особенности красных столовых виноматериалов из сорта винограда Каберне-Совиньон, произрастающего в некоторых зонах Крыма //«Магарач». Виноградарство и виноделие. 2018. № 2 (104). С. 34-37.

[Makarov A.S., Yalaneckij A.Ya., Shmigelskaya N.A., Lutkov I.P., Shalimova T.R., Maksimovskaya V.A., Krechetova V.V. Peculiarities of red table wine materials made from 'CabernetSauvignon' grapes cultivated in certain areas of Crimea. Magarach. Vinogradarstvo $i$ vinodelie= Magarach. Viticulture and Winemaking. 2018. № 2 (104). pp. 34-37 (in Russian)].

9. The impact of soil properties on nutrient availability and fruit and wine characteristics in a PasoRobles vineyard /J.J. Lambert, R.A. Dahlgren, M. Battany. Proceedings of the 2-nd Annual National Viticulture Research Conference, July 9-11, 2008. University of California, Davis. 2008.

10. Остроухова Е.В., Пескова И.В., Пробейголова П.А., Луткова Н.Ю. К вопросу о создании информационных моделей технологических параметров винограда сорта Каберне-Совиньон, произрастающего в Крыму// Проблемы развития АПК региона. 2018. № 3 (35). С. 184-193.

[Ostroukhova E.V., Peskova I.V., Probeigolova P.A., Lutkova N.Yu. On the issue of creating information models of technological parameters of 'Cabernet-Sauvignon' grapes growing in Crimea. Problems of development of agribusiness in the region. 2018. № 3 (35). pp. 184-193 (in Russian)].

11. Е.В. Остроухова, И.В. Пескова, П.А. Пробейголова, В.В. Кречетова Химический состав, физико-химические свойства белых и красных десертных вин из разных природноклиматических зон Крыма // «Магарач». Виноградарство и виноделие. 2014. № 4. С. 21-24.

[Ostrouhova E.V., Peskova I.V., Probejgolova P.A., Krechetova V.V. Chemical composition and physico-chemical properties of white and red dessert wines from various climatic regions of Crimea. Magarach. Vinogradarstvo $i$ vinodelie=Magarach . Viticulture and Winemaking. 2014. № 4. pp. 21-24 (in Russian)].

12. Таран Н.Г, Пономарева И.И. Влияние сорта винограда и зоны его произрастания на качество виноматериалов для игристых вин // Науч. тр. ГНУ «СКЗНИИСиВ» - 2013. - Т. 4. - C. 241-245.

[Taran N.G., Ponomareva I.I. The influence of grapevine cultivar and zones of its origin on the quality of wine materials for sparkling wines. Scientific works of the State scientific institution of the North-Caucasian Zonal Scientific Research Institute of Gardening and Winemaking of the Russian Academy of Agricultural Sciences. 2013. Vol. 4. pp. 241-245 (in Russian)].

13. Червяк С.Н. Изучение взаимосвязей физико-химических и биохимических показателей винограда технических сортов // Научные труды Кубанского государственного технологического университета. - 2018. - № 1 (362). - С. 1-10.

[Cherviak S.N. Relationship analysis between physicochemical and biochemical indicators of the grapes used for winemaking. Scientific works of the Kuban State Technological University. 2018. № 1 (362). pp. 1-10 (in Russian)].

14. Jackson D.J., Lombard P.B. Environ-mental and Management Practices Affecting Grape Composition and Wine Quality // A Review Department of Horticulture \& Landscape: Lincoln University. Vitic. 1993. Vol.44. №4. P. 409-430.
15. Dynamics of phenolic components during the ripening of grapes from sub-mediterranean climatic zone of the Crimea: influence on the quality of red wines/ Levchenko S.V., Ostroukhova E.V., Peskova I.V., Probeigolova P.A. I International Conference \& X National Horticultural Science Congress of Iran (IrHC2017) Abstracts book. 2017. P. 261.

16. The quality of grapes and the efficient ways in winemaking/ S.V.Levchenko, E.V.Ostroukhova, I.V.Peskova, P.A. Probeigolova. International symposium on horticulture: Priorities and emerging trends Bengaluru (India), 05-08 September 2017.

17. Ashenfelter O., Storchmann K. Climate change and wine: A review of the economic implications. Journal of Wine Economics. 2016. Vol.11. №1. p. 105-138.

18. Darriet P. Influence of environmental stress on secondary metabolite composition of Vitis vinifera var. Riesling grapes in cool climate region - water status and sun exposure // Oenologie 2011, Proceedings of the 9th Symposium International d'Oenologie, Bordeaux, June 15-17. 2011. p. 65-70.

19. Cadot Y. Flavan-3-ol compositional changes in grape berries (Vitis vinifera L. cv Cabernet Franc) before veraison, using two complementary analytical approaches, HPLC reversed phase and histochemistry/Y. Cadot, M. T. Minana Castello, M. Chevalier. Anal. Chim. Acta. 2006. № 563. P. 65-75.

20. Методы технохимического контроля в виноделии / Под ред. Гержиковой В.Г. - 2-е изд. - Симферополь: Таврида, 2009. 304 c.

[Techno-chemical control methods in winemaking / Ed. Gerzhikova V.G. 2nd ed. Simferopol: Tavrida, 2009. 304 p. (in Russian)].

21. Бурьян Н.И. Микробиология виноделия / 2-е издание, дополненное. - Симферополь: Таврия, 2002 - 433 с.

[Buryan N.I. Microbiology of winemaking / 2nd edition, extended. Simferopol: Tavria, 2002. 433 p. (in Russian)].

22. Макаров А.С. Производство шампанского / Под ред. Валуйко Г. Г. - Симферополь: Таврида, 2008. - 414 с.

[Makarov A.S. Champagne Production / Ed. Valujko G.G. Simferopol: Tavrida, 2008. 414 p. (in Russian)].

23. Косюра В.Т. Игристые вина. История, современность и основные направления производства: монография. - Краснодар, 2006. - 504 с.

[Kosyura V.T. Sparkling wines. History, modernity and main directions of production: monograph. Krasnodar, 2006. 504 p. (in Russian)].

24. L. Gambelli, G.P. Santaroni Polyphenols content in some Italian red wines of differentgeographical origins. Journal of Food Composition and Analysis. 17 (2004). pp. 613-618.

25. Alvaro Peña-Neira. Chapter 18: Management of Astringency in Red Wines. Red Wine Technology, 2019. PP. 257-272.

26. Phenolic compositions of grapes and wines from cultivar Cabernet Sauvignon produced in Chile and their relationship to commercial value / A. Cáceres-Mella, A. Peña-Neira, A. Galvez, E. Obreque-Slier, R. López-Solís, J.M. Canals. J. Agric. Food Chem. 60 (35) (2012). pp. 8694-8702.

27. J.L. Landon, K. Weller, J.F. Harbertson, C.F. Ross / Chemical and sensory evaluation of astringency in Washington state red wines. Am. J. Enol. Vitic. 59 (2008), pp. 153-158.

ORCID ID:

Макаров A.C. https://orcid.org/0000-0001-8497-5056

Шмигельская H.A. https://orcid.org/0000-0002-1244-8115

Лутков И.П. https://orcid.org/0000-0001-9515-4341

Васылык А.В. https://orcid.org/0000-0002-0546-4141

Максимовская B.A. https://orcid.org/000-0002-2867-7510

Шалимова T.P. https://orcid.org/0000-0002-1749-0419 